\title{
COM DNE

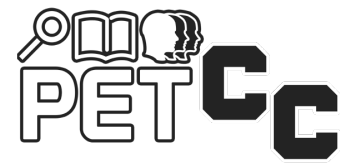

\section{Semana da Computação da UFJF: desafios e perspectivas entre os anos de 2017 e 2019}

\author{
Carlos Alexandre de Almeida Pires ${ }^{1}$, Igor de Oliveira Knop ${ }^{1}$, \\ Ruy Freitas Reis ${ }^{1}$, Bárbara de Melo Quintela ${ }^{1}$ \\ ${ }^{1}$ Universidade Federal de Juiz de Fora (UFJF) \\ Juiz de Fora, Minas Gerais - Brasil \\ carlos.alexandredengenharia.ufjf.br, igorknopdice.ufjf.br, \\ ruy.reis@ufjf.br, barbaradice.ufje.br
}

\begin{abstract}
The UFJF Computing Week is an extension/outreach event that has been taking place for over 20 years. With the help of Tutorial Education groups in the area of computing at the Federal University of Juiz de Fora (UFJF), the event has several contents aimed at the integral development of computing students. This article presents the challenges of the organization and the importance of the event, focusing on the 2017, 2018 and 2019 editions. The results demonstrate an excellent participation of the courses involved and their contribution to improving the quality of student training.
\end{abstract}

Resumo. A Semana da Computação da UFJF é um evento de extensão que acontece há mais de 20 anos. Com o auxílio dos grupos de Educação Tutorial da área de computação na Universidade Federal de Juiz de Fora (UFJF), o evento possui uma programação bastante variada voltada para o desenvolvimento integral dos estudantes de computação. Este artigo apresenta os desafios da organização e a importância do evento, focando nas edições de 2017, 2018 e 2019. Os resultados demonstram uma ótima participação dos cursos envolvidos e a sua contribuição para a melhoria da qualidade da formação dos estudantes.

\section{Introdução}

As instituições de ensino superior (IES) têm o seu papel no desenvolvimento integral dos seus estudantes no aspecto profissional e pessoal, sem esquecer de trazer uma formação mais humanizada para que os estudantes sejam mais comprometidos a agir, através da sua atuação profissional, no combate aos problemas sociais [Arroyo and Rocha 2010].

As disciplinas presentes na grade curricular dos cursos da computação nem sempre são suficientes para os alunos obterem noções de mercado de trabalho, autoconfiança e as chamadas soft skills, principalmente na sua vida profissional logo após a formatura. Com isso, diversas universidades organizam atividades que aproximam os estudantes das principais novidades e oportunidades da área da computação. No caso dos cursos de computação da Universidade Federal de Juiz de Fora (UFJF) - composto pelos cursos de bacharelado em Ciência da Computação (Integral e Noturno), Engenharia Computacional, Sistemas de Informação e Licenciatura em Computação - uma das principais atividades voltadas para o aprimoramento dos discentes é a Semana da Computação da UFJF, o qual é elaborado e organizado de forma democrática e participativa pelo corpo docente do Departamento de Ciência da Computação (DCC) e discentes dos cursos supracitados. 
Também, é um dos eventos que compõem a Semana do Instituto de Ciências Exatas (ICE) da UFJF, o qual, há mais de 20 anos, reúne todas as semanas acadêmicas dos departamentos do instituto (Estatística, Química, Matemática, Física e Ciência da Computação) e, nos últimos anos, coincide com a realização da Semana Nacional de Ciência e Tecnologia, uma ação ao nível nacional mobilizada pelo Ministério da Ciência, Tecnologia e Inovações (MCTI) instituída a partir do decreto de 9 de junho de 2004 [Brasil 2004]. Com a reunião das semanas acadêmicas do ICE, também é realizada uma feira de ciências, de trabalhos elaborados por estudantes das escolas de ensino fundamental e médio, públicas e particulares, de Juiz de Fora e região [UFJF 2018]. E uma mostra dos cursos do instituto com a participação da comunidade acadêmica do instituto e de segmentos estudantis da Faculdade de Engenharia, como equipes de competição e o Ramo Estudantil IEEE (Figura 1).



Figura 1. Mostra da equipe de competição Rinobot Team, durante a XXIX Feira de Ciências do ICE em 2018, para estudantes do ensino básico.

Desde a criação dos primeiros grupos de educação tutorial da área de computação da UFJF, no início dos anos 2010, o DCC incentiva ativamente participação dos grupos de educação tutorial neste evento, inclusive abrindo espaço para estes alunos ofertarem minicursos e palestras na programação. Com isso, possibilita a divulgação e o impacto das atividades dos grupos para todos os estudantes do ICE.

O objetivo deste artigo é discutir e relatar os desafios da realização e a importância da Semana da Computação da UFJF, com o envolvimento dos grupos de educação tutorial, nas edições ocorridas, nos anos de 2017, 2018 e 2019.

\section{Os grupos de educação tutorial da área de computação na UFJF}

A UFJF possui 6 grupos do Programa de Educação Tutorial (PET), filiados à Secretaria do Ensino Superior/Ministério da Educação (SeSU/MEC), e 13 Grupos de Educação Tutorial (GET) e seu funcionamento é de responsabilidade da Pró-Reitoria de Graduação da UFJF. $\mathrm{Na}$ área da computação, têm-se 3 grupos, os dos cursos de Ciência da Computação (GET 
Comp), Engenharia Computacional (GET EngComp) e Sistemas de Informação (GET SI).

GET Comp e GET EngComp foram criados em 2010, no primeiro edital da criação dos GETs na universidade. E o GET SI foi criado em 2018, no segundo edital de criação do GETs. Todos eles, possuem incluem atividades de ensino, pesquisa e extensão, tais como atividades de iniciação científica, desenvolvimento de monitoria e minicursos, participações em ações de extensão, organização de eventos, entre outras atividades.

\section{Estruturação da Semana da Computação}

É realizada nas dependências do ICE, no campus sede da UFJF. Para o incentivo da participação discente e a liberação do espaço, o departamento não oferta aula durante o evento. Em todas as edições, possui diversas palestras e minicursos (Figuras 2 e 3). Nos últimos anos, foi visto também na Semana da Computação visitas técnicas, noite de jogos e feira de empresas, com oportunidades de estágio. É aberto a todo o público acadêmico e à comunidade externa, com programação de manhã, tarde e noite devido à existência de cursos no período integral e noturno. Nas três edições, 2017 a 2019, a duração foi de três dias.

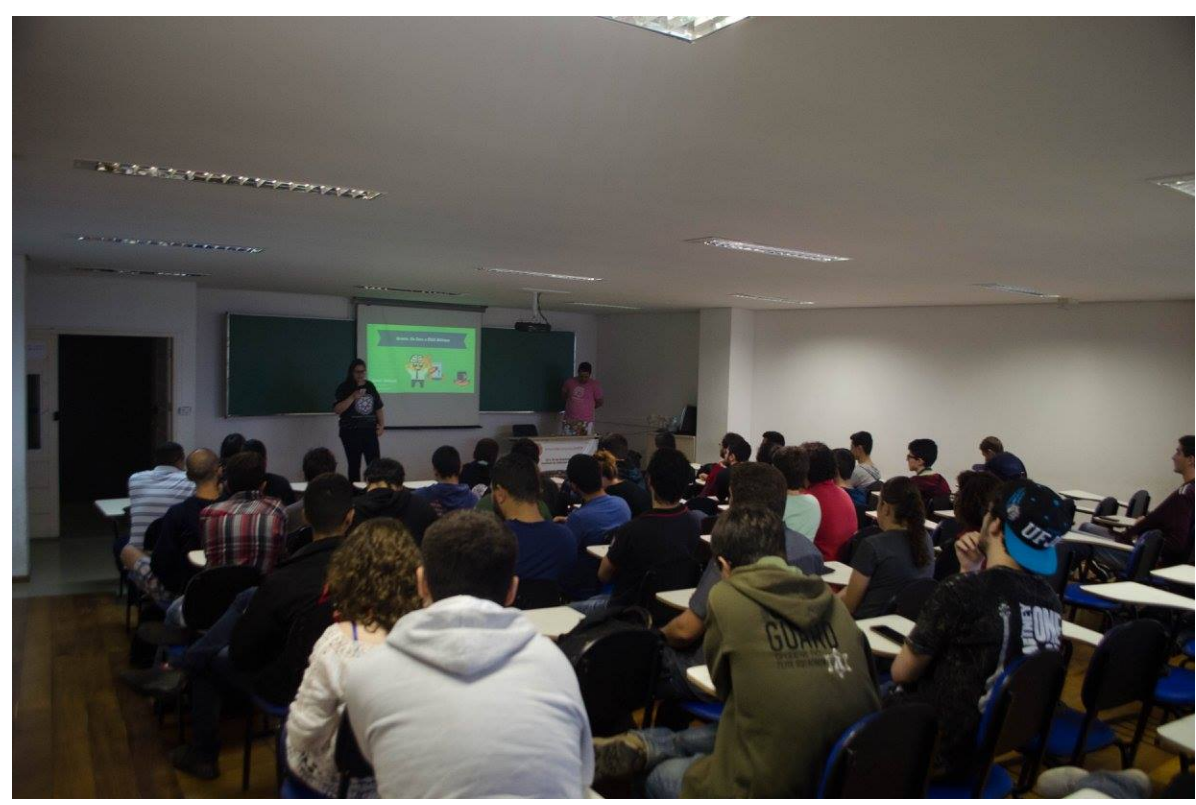

Figura 2. Palestra na Semana da Computação da UFJF em 2017.

As atividades do tipo minicurso geralmente tem duração de $4 \mathrm{~h}$, já as palestras tem duração de $1 \mathrm{~h}$ (incluindo a apresentação e perguntas). Foi priorizado que os minicursos seriam realizados nos turnos matutino e vespertino e as palestras no turno noturno na tentativa de atender à demanda dos discentes de todos os cursos e possibilitar maior participação nas palestras por parte dos discentes que realizam estágios e/ou outras atividades profissionais durante o dia. Foram ofertados minicursos no turno da noite também em paralelo com alguns eventos. A comissão buscou colocar em paralelo apenas as atividades que representassem diversos interesses. 


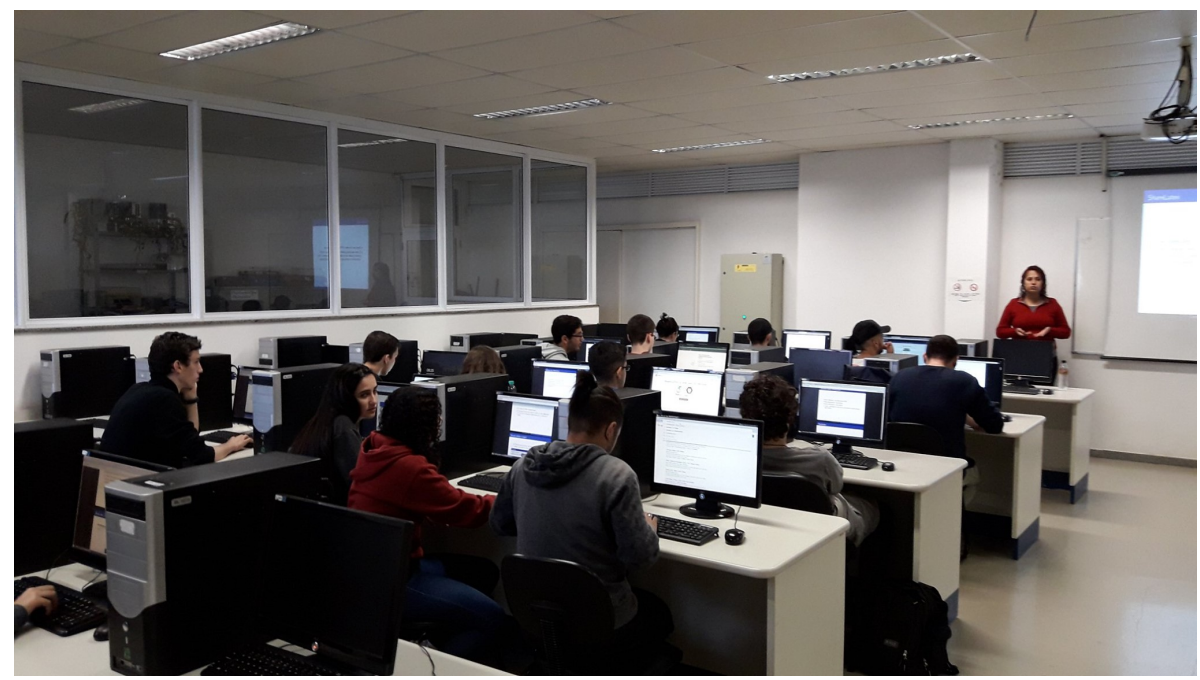

Figura 3. Minicurso ofertado na Semana da Computação em 2019.

\subsection{Comissão organizadora}

No início do segundo semestre de cada ano, geralmente, o Departamento de Ciência da Computação decide internamente os professores, por volta de 3 docentes, que serão membros da comissão organizadora da Semana da Computação do ano. A comissão de docentes buscam discentes para o apoio, que geralmente não ultrapassam 8. É incentivada a participação de docentes mais recentes no departamento, mas não é uma regra. Em 2017, o departamento permitiu os discentes organizarem o evento com o auxílio de uma docente. Entre os discentes da comissão organizadora da edição de 2017, metade eram oriundos de GETs.

Por não ter um número expressivo de integrantes na comissão organizadora, não é usual separar em subcomitês para atribuições tipicas de um evento (comunicação, infraestrutura, financeiro, comunicação). Por outro lado, cada pessoa possui uma responsabilidade, segundo as necessidades da Semana da Computação e a sua disponibilidade, mantendo um foco nas tarefas e proximidade com outros integrantes para sanar desafios em conjunto, principalmente ajustar situações que precisam do envolvimento de mais de uma pessoa. No final do evento, todos os integrantes que estiveram presentes e cumpriram com as suas responsabilidades, recebem um certificado de participação na comissão organizadora ou de apoio, se for o caso.

\subsection{Definição do conteúdo e busca de patrocínio}

Inicialmente, alguns meses antes da realização, é feito uma pesquisa de opinião da comunidade acadêmica, possibilitando a participação da sociedade, com a possibilidade de indicar conteúdos que gostariam de colocar na programação do evento, preferências por linguagens de programação, pessoas para ofertarem conteúdos, contato de empresas para patrocínio e divulgação de estágio, além de observações gerais. Com esses dados, é feito uma seleção dos assuntos para a busca de conteúdo (contato com possíveis palestrantes, ministrantes e definição da grade horária). Em paralelo, contacta-se empresas que possam se interessar pela temática ou público-alvo da Semana da Computação ou ofertar algum serviço necessário para eventos em geral, como coffee break, para patrocínio ou alguma parceria para o sorteio de brindes ou conteúdo adicional. 
Os temas abordados nas três últimas edições são, em sua grande maioria, orientados para o mercado de trabalho, mas alguns são voltados para a área acadêmica. Também, possui espaço para assuntos voltados para os cursos, exemplificando a mesa redonda sobre a vivência interdisciplinar da Computação e Engenharia, comemorando os 10 anos de criação do curso de Engenharia Computacional na edição de 2018, organizada pelo GET EngComp. Nos últimos anos, tem sido organizadas maratonas de programação (Figura 4), diferenciando discentes nos períodos iniciais dos mais avançados.

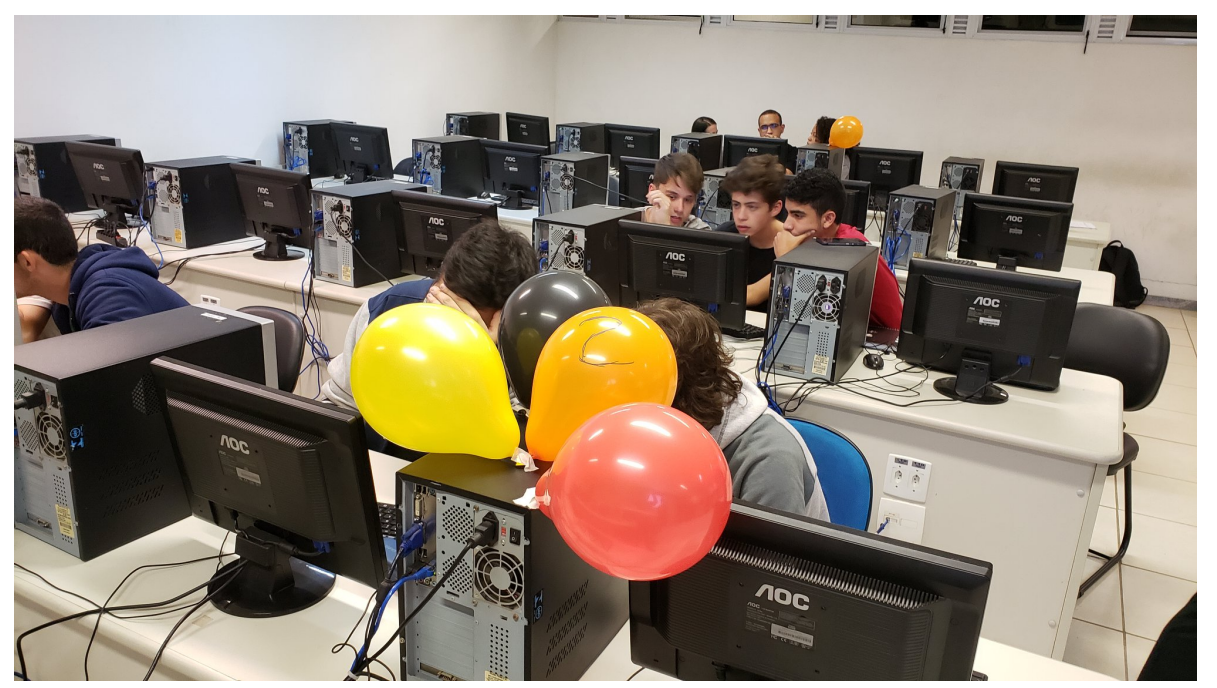

Figura 4. Maratona de programação júnior na Semana da Computação da UFJF em 2019.

Também, em algumas das edições mais recentes, realizou-se uma noite de jogos, incluindo jogos de tabuleiro e de videogame, conforme Figura 5. Assim, proporcionando uma interação entre os participantes. Antes da Semana da Computação, a noite de jogos só era presente em confraternizações dos estudantes da área de computação.

Após a definição dos temas, a Comissão Organizadora entra em contato com os professores e representantes discentes de graduação e pós-graduação para verificar se tem interesse em apresentar alguma palestra ou minicurso. Nas ultimas edições, os GETs tem atuado não apenas no apoio à organização de diversos eventos Semana da Computação, mas também oferecendo minicursos.

\subsection{Principais desafios}

Como todo evento de diferentes realidades, as comissões organizadoras das últimas edições da Semana da Computação enfrentam desafios durante a realização da mesma. Um dos principais pontos é a obtenção de patrocínio suficiente para trazer palestrantes externos à universidade, dando aos participantes do evento conteúdo de profissionais da computação que não estão habituados no dia a dia da sua vivência universitária, melhorando o interesse do público-alvo e o seu engajamento para maior presença. Já ocorreu de palestrantes externos custearem a sua própria ida ao evento, com o propósito de trazer um conteúdo de qualidade para os participantes do evento.

Outro desafio nas últimas edições é a obtenção dos insumos para realizar os coffee breaks, entre os intervalos do evento. Como são oferecidos eventos durante os turnos 


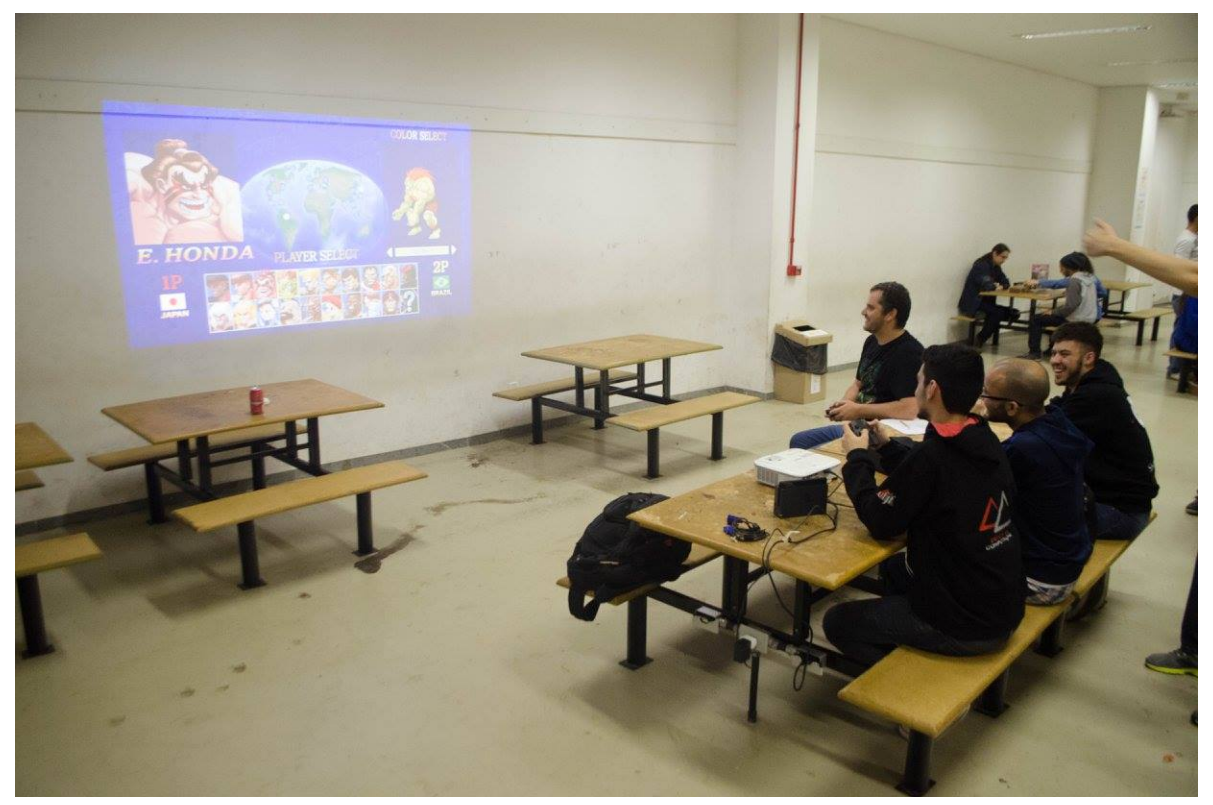

Figura 5. Noite de jogos na Semana da Computação da UFJF em 2017.

manhã, tarde e noite, é importante oferecer coffee breaks para que os participantes que queiram acompanhar eventos em mais de um turno não precisem deixar o local. Para escapar da falta de recursos, foram buscados parceiros da área de alimentação para fazerem divulgação no evento, inclusive entrega de panfletos, em troca de ofertar alimentos para o coffee break.

Por fim, a montagem dos horários foi um desafio para a comissão para otimizar o evento com mais conteúdos e, em simultâneo, colocar em horários que é visível a maior participação. Para permitir maior participação nos eventos da Semana do ICE, a direção do instituto libera os estudantes das aulas acadêmicas para a participação nos eventos associados, além de alguns docentes exigirem de seus alunos uma comprovação de presença em, pelo menos, uma palestra no evento associado a área de interesse. $\mathrm{Na}$ Semana da Computação, prioriza-se os horários de tarde e da noite para as palestras, mantendo durante a manhã minicursos com o início a partir das $8 \mathrm{~h}$ ou $9 \mathrm{~h}$.

\section{Resultados}

Em cada uma das três últimas edições do evento, participaram por volta de 300 pessoas, em sua grande maioria estudantes da área de computação da UFJF. Em algumas palestras chegaram a ter 90 pessoas assistindo, o que mostra êxito na qualidade do evento. A maratona de programação foi bastante procurada, próxima da quantidade máxima de participantes.

Considerando a quantidade de inscrições recebidas nas palestras e minicursos, não necessariamente a quantidade de participantes pois podem inscrever em mais de uma atividade, é mais expressiva nos períodos da tarde e da noite, como pode ser visto nas Tabelas 1 e 2, mesmo quando possui. Isso pode ser explicado pela disponibilidade dos estudantes do turno noturno, em geral, ser restrita na parte da manhã e no início da tarde.

Sobre a frequência média das atividades, é relativamente alta, com poucas ocorrências de ser abaixo de $60 \%$, o qual provavelmente é devido a liberação das aulas por 
parte dos departamentos do ICE e a exigência de alguns professores de seus estudantes irem nas atividades da Semana da Computação para computar frequência.

Tabela 1. Frequência média dos participantes nos minicursos ofertados na Semana da Computação da UFJF entre os anos de 2017 e 2019.

\begin{tabular}{|c|c|c|c|c|c|c|c|c|c|}
\cline { 2 - 10 } \multicolumn{1}{c|}{} & \multicolumn{3}{c|}{ Manha } & \multicolumn{3}{c|}{ Tarde } & \multicolumn{3}{c|}{ Noite } \\
\cline { 2 - 11 } & $\mathbf{2 0 1 7}$ & $\mathbf{2 0 1 8}$ & $\mathbf{2 0 1 9}$ & $\mathbf{2 0 1 7}$ & $\mathbf{2 0 1 8}$ & $\mathbf{2 0 1 9}$ & $\mathbf{2 0 1 7}$ & $\mathbf{2 0 1 8}$ & $\mathbf{2 0 1 9}$ \\
\hline Número de Inscrições & 182 & 236 & 227 & - & 218 & 157 & 157 & 164 & 56 \\
\hline Frequência Média & - & 67,4 & 70,5 & - & 64 & 67,7 & - & 52,4 & 66,1 \\
\hline Quantidade & 4 & 6 & 6 & 0 & 4 & 4 & 2 & 3 & 1 \\
\hline
\end{tabular}

Tabela 2. Frequência média dos participantes nas palestras ofertadas na Semana da Computação da UFJF entre os anos de 2017 e 2019. Não foram ofertadas palestras no turno da manhã nas edições analisadas.

\begin{tabular}{|c|r|c|c|c|c|c|}
\cline { 2 - 7 } \multicolumn{1}{c|}{} & \multicolumn{3}{c|}{ Tarde } & \multicolumn{3}{c|}{ Noite } \\
\cline { 2 - 7 } \multicolumn{1}{c|}{} & $\mathbf{2 0 1 7}$ & $\mathbf{2 0 1 8}$ & $\mathbf{2 0 1 9}$ & $\mathbf{2 0 1 7}$ & $\mathbf{2 0 1 8}$ & $\mathbf{2 0 1 9}$ \\
\hline Número de Inscrições & 658 & 151 & 34 & 582 & 560 & 596 \\
\hline Frequência Média & - & 69,2 & 76,5 & - & 47,7 & 73,5 \\
\hline Quantidade & 8 & 3 & 2 & 6 & 11 & 11 \\
\hline
\end{tabular}

O auxílio na mostra dos cursos do ICE, por parte da comissão organizadora da Semana da Computação, teve a participação de 300 estudantes e professores da rede básica do ensino, promovendo os cursos de graduação da UFJF e falar sobre a importância da função destes egressos para a sociedade.

Após o evento, nas reuniões da comissão para finalizar as pendências, vários docentes e alunos da UFJF mostram um feedback positivo geral do evento, com o trabalho dos grupos de Educação Tutorial.

\section{Conclusão}

A descrição de todo o planejamento e a explicitação dos resultados do maior evento de computação da UFJF, pode servir como guia para as próximas edições do evento e, também, de outros eventos de mesma natureza de todo o Brasil. Além disso, a participação massiva dos estudantes no evento reforça o interesse dos mesmos em aprofundar em oportunidades e caminhos na vida profissional, e traz uma outra visão da Computação, porém mais prática.

Como a Semana da Computação da UFJF já existia antes da criação dos grupos, a participação discente na organização do evento aumentou depois da inserção dos grupos GET, trazendo um protagonismo estudantil e, consequentemente, melhorando a programação por corresponder as expectativas do público-alvo. Além disso, como os integrantes dos GETs são alunos dos cursos, eles também possuem uma aproximação maior com os discentes, facilitando a troca de informações.

Também, trazer conteúdos que nem sempre são possíveis de serem vistos na sala de aula faz que os estudantes se sentirem mais motivados pela área, diminuindo evasões, e por terem um momento de confraternização na universidade, criando um ambiente mais agradável e ativo na formação dos futuros profissionais de computação. 
Para as futuras edições, o principal desafio é manter a programação atrativa e atualizada, de acordo com os avanços da computação. Também, é cada vez mais sugerido por professores do departamento na oferta de algumas atividades de forma híbrida, permitindo a participação de mais palestrantes internacionais sem custos de transporte e hospedagem.

\section{Referências}

Arroyo, D. M. P. and Rocha, M. S. P. D. M. L. D. (2010). Meta-avaliação de uma extensão universitária: estudo de caso. Avaliação: Revista da Avaliação da Educação Superior (Campinas), 15:131-157.

Brasil (2004). Decreto de 9 de maio de 2004. Institui a Semana Nacional de Ciência e Tecnologia. Diário Oficial da União.

UFJF (2018). Semana do ICE celebra 50 anos do Instituto. https : / /www2 . uf jf . br/noticias/2018/10/11/semana-do-ice-celebra-50-anos-doinstituto/. [Online: Acesso em 01-Outubro-2021]. 